\title{
Space and time-related firing in a model of hippocampo-cortical interactions
}

\author{
Julien Hirel ${ }^{1 *}$, Philippe Gaussier ${ }^{1}$, Mathias Quoy ${ }^{1}$, Jean-Paul Banquet ${ }^{2}$, Bruno Poucet $^{3}$ \\ From Nineteenth Annual Computational Neuroscience Meeting: CNS*2010 \\ San Antonio, TX, USA. 24-30 July 2010
}

The present work is part of a project aiming at modeling the hippocampo-cortical interactions in order to solve complex navigation tasks. It is the result of a long partnership between neurobiologists and computer scientists. A close feedback loop between in vivo experiments and computer models leads us to produce biologically accurate neural networks used in robotic navigation.

Place cells are pyramidal neurons of the hippocampus (Hs) exhibiting high rates of firing at a particular location in the environment, corresponding to the cell's "place field". In a task where rats have to navigate to a goal location and wait for a reward, we recently observed the timing prediction capabilities of CA place cells [1]. This "out-of-field" firing was recorded at the goal location, far from the original place fields of the cells. These patterns of activity are suggested to spread from the Hs to the medial prefrontal cortex (mPFC) where similar activities were observed [2].

\section{Methods}

In a previous model [3], a spectral timing neural network [4] was used to account for the role of the Hs in the acquisition of classical conditioning. The ability to estimate the timing between separate events was then used to learn and predict transitions between places in the environment. We propose a neural architecture based on this work and explaining the out-of-field activities in the Hs along with their temporal prediction capabilities. The model uses the hippocampo-cortical pathway as a means to spread reward signals to entorhinal neurons. Secondary predictions of the reward signal are then learned, based on transition learning, by pyramidal neurons of the CA region.

\footnotetext{
* Correspondence: julien.hirel@ensea.fr

${ }^{1}$ Neurocybernetic team, ETIS, CNRS - ENSEA - Université de Cergy-Pontoise, Cergy-Pontoise, France, 95000
}

\section{Results}

The architecture was implemented in a simulated environment. An agent learned to navigate to a goal location and wait for a reward with the supervision of the experimenter. The results match neurophysiological observations in several ways:

1) Recorded neural activities in hippocampal place cells display out-of-field firing, predictive of the reward at the goal location, in addition to the usual firing on the primary place field.

2) Timing-related firing in the Hs is propagated to the mPFC. This is coherent with observations of the abolition of such activity in the mPFC following hippocampal lesions in rats.

3) The mPFC only plays a role during the learning phase of the secondary associations. This is consistent with neurophysiological data on the lack of effect of mPFC inactivation on out-of-field firing in the Hs after learning.

Our model is realistic and makes testable hypotheses as to the neural pathways involved. In vivo experiments will be conducted to confirm or infirm those hypotheses. Future work involves testing the system on a real robot in large scale environments.

\section{Acknowledgements}

This project was supported by the Centre National de la Recherche Scientifique (CNRS) and the Delegation Generale pour l'Armement (DGA)

\section{Author details}

${ }^{1}$ Neurocybernetic team, ETIS, CNRS - ENSEA - Université de Cergy-Pontoise, Cergy-Pontoise, France, 95000. ${ }^{2}$ Neurosciences and modelisation institute, INSERM 742, UPMC, Jussieu, Paris, France. ${ }^{3}$ Laboratory of Neurobiology and Cognition (LNC), CNRS - Université d'Aix-Marseille, Marseille, France.

\section{Published: 20 July 2010}

\section{References}

1. Hok V, Lenck-Santini PP, Roux S, Save E, Muller RU, Poucet B: Goal-related activity in hippocampal place cells. J Neurosci 2007, 27(3):472-482. 
2. Burton BG, Hok V, Save E, Poucet B: Lesion of the ventral and intermediate hippocampus abolishes anticipatory activity in the medial prefrontal cortex of the rat. Behav Brain Res 2009, 199(2):222-234.

3. Banquet JP, Gaussier P, Dreher JC, Joulain C, Revel A, Günther W: Spacetime, order, and hierarchy in fronto-hippocampal system: A neural basis of personality. Cognitive science perspectives on personality and emotion Amsterdam: Elsevier ScienceG. Matthews 1997, 123-179.

4. Grossberg S, Schmajuk NA: Neural dynamics of adaptive timing temporal discrimination during associative learning. Neural Netw 1989, 2(2):79-102.

doi:10.1186/1471-2202-11-S1-P163

Cite this article as: Hirel et al: Space and time-related firing in a model of hippocampo-cortical interactions. BMC Neuroscience 2010 11(Suppl 1): P163.

Submit your next manuscript to BioMed Central and take full advantage of:

- Convenient online submission

- Thorough peer review

- No space constraints or color figure charges

- Immediate publication on acceptance

- Inclusion in PubMed, CAS, Scopus and Google Scholar

- Research which is freely available for redistribution

Submit your manuscript at www.biomedcentral.com/submit 